\title{
Progesterone vaginal ring: Beneficial role in birth spacing
}

Population Council

Follow this and additional works at: https://knowledgecommons.popcouncil.org/departments_sbsr-rh

Part of the Demography, Population, and Ecology Commons, Family, Life Course, and Society Commons, International Public Health Commons, Maternal and Child Health Commons, and the Women's Health Commons How does access to this work benefit you? Let us know!

\section{Recommended Citation}

"Progesterone vaginal ring: Beneficial role in birth spacing," Project brief. New York: Population Council, 2015.

This Brief is brought to you for free and open access by the Population Council. 


\section{PROGESTERONE VAGINAL RING BENEFICIAL ROLE IN BIRTH SPACING}

\section{The Progesterone Vaginal Ring (PVR) is a vaginal ring which contains progesterone and can enhance the effect of breastfeeding on birth spacing.}

\section{CONTRACEPTIVE EFFECT OF EXCLUSIVE BREASTFEEDING}

Postpartum family planning has received renewed focus with the issuance of new guidelines from the World Health Organization; some estimates of unmet need for contraception among women during the postpartum period are more than $60 \%$ in developing countries ${ }^{1,2}$.

In this context, the lactational amenorrhea method (LAM) is recognized as an effective means of postponing the return to fertility in breastfeeding mothers as indicated by the onset of menstrual bleeding ${ }^{3-9}$. LAM is defined as a method that can effectively protect a woman from pregnancy if she meets all of the following three criteria: 1) Her period has not returned since her baby was born; 2) She is breastfeeding exclusively (fully) day and night, i.e. breast milk is the only source of water or nutrients during the first six months as long as the infant's growth is adequate; 3 ) Her baby is less than six months old. As soon as the woman no longer meets one of these criteria, pregnancy rates increase and she needs to begin using another contraceptive method.

Based on recent DHS surveys, however, a low proportion of women report compliance with the three criteria for the use of LAM in DHS surveys (usually less than $5 \%$ of breastfeeding women $)^{10}$, although results from a large multicenter study on efficacy of LAM conducted in the early 1990s, suggest that deviation from specific use of each of the three criteria does not cause a significant upsurge in pregnancy rates ${ }^{11}$. It has been shown that the PVR as a new method of contraception during lactation, can provide additional protection to breastfeeding women who want to space their pregnancies for more than one year, but may not comply with the strict criteria of LAM.

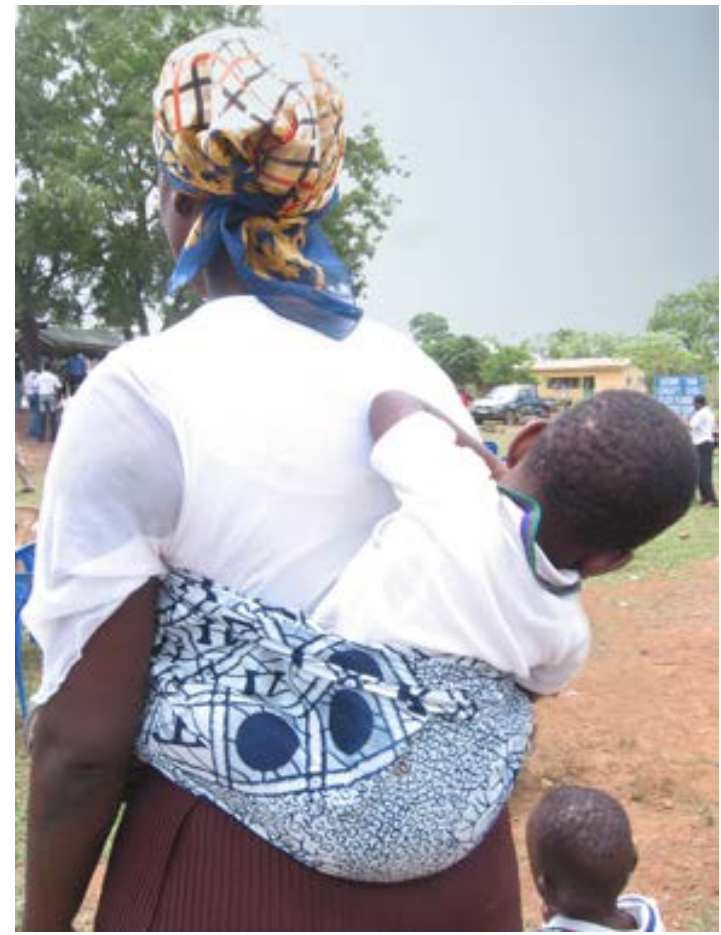

Lactational amenorrhea and its associated infertility have been shown to contribute to birth spacing, although variable effectiveness has been reported among different communities. In a population of highly motivated Chilean women $(n=236)$ who breastfed up to 8 times per day, the risk of experiencing the first bleeding was reduced while fully breastfeeding with a high number of nursing episodes per day and night, but $25 \%$ and $50 \%$ of the women had started to cycle by the end of the fifth and eight postpartum month respectively ${ }^{3}$.

After the first postpartum menses, the risk of pregnancy for breastfeeding women increases substantially3,12. The cumulative probability of pregnancy changes from $0.9 \%$ in amenorrheic women to $36 \%$ in cycling women at 6 months
The Population Council conducts research and delivers solutions that improve lives around the world. Big ideas supported by evidence: It's our model for global change. popcouncil.org
POPULATION COUNCIL

Ideas. Evidence. Impact. 
postpartum; and at 12 months, the pregnancy rate increases further from $17 \%$ (in amenorrheic women) to $55 \%$ (in cycling women) ${ }^{12}$.

Diaz et $\mathrm{al}^{4}$ demonstrated that the onset of bleeding before the sixth postpartum month, in fully breastfeeding women, predicts a higher risk of pregnancy. The investigators calculated the probability of experiencing the first bleeding and the probability of pregnancy in 236 women who were fully breastfeeding and not using contraception and enrolled during the first month postpartum ${ }^{4-11}$. The cumulative probability of bleeding and of pregnancy was $52 \%$ and $9.4 \%$ at day 180 postpartum, respectively. The risk of pregnancy was less than $2 \%$ in the subset of amenorrheic women ${ }^{4}$. These results confirmed that lactational amenorrhea provides effective contraceptive protection during the first six months postpartum. They also suggested that the first postpartum bleeding marks a discernible increase in the risk of pregnancy 4,12 .

After the sixth month postpartum, when breastfeeding will probably cease to be "full" or nearly full, it is increasingly likely that ovulation will precede the first vaginal bleed. Therefore, the protection against pregnancy that is afforded by breastfeeding decreases over time to levels lower than those of other family planning methods ${ }^{5}$.

Based on these data, participants in a Bellagio consensus conference ${ }^{5}$ concluded that the maximum birth spacing effect of breastfeeding is achieved when a mother "fully" or nearly fully breastfeeds and remains amenorrheic. When these two conditions are fulfilled, breastfeeding provides more than $98 \%$ protection from pregnancy in the first six months ${ }^{5}$.

\section{CONTRACEPTIVE METHODS IN BREASTFEEDING WOMEN}

As a result of the growing urbanization and changing social norms about the role of women in developing countries, the duration of exclusive breastfeeding and its impact as a contraceptive strategy has been reduced. This situation has given rise to the need for a contraceptive method that could extend the infertile period following delivery, especially in countries where access to other contraceptives is limited and where longer duration of breastfeeding is a social norm and a major benefit to infant health.

According to WHO Medical Eligibility Criteria (MEC), several methods are suitable for women who are breastfeeding and can be recommended ${ }^{13}$. Progestin-only pills (POP) have a longer half-life than progesterone, but need to be taken daily at approximately the same time. Long-acting methods such as the progestin implant or an intrauterine device (IUD) require access to trained health care providers for insertion and removal. The PVR was developed as a new user-controlled method that delivers a natural hormone for 3 consecutive months, hence not requiring daily attention by the user. Progesterone is metabolized quickly after ingestion in breast milk, limiting the steroid exposure to the infant.

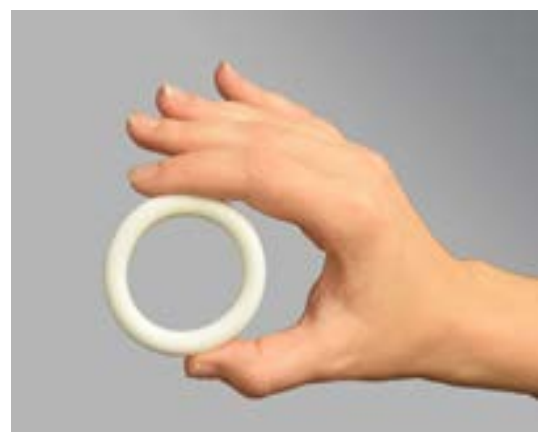

MECHANISM OF ACTION OF THE PVR

The contraceptive mechanism of action of natural progesterone is similar to that of progestin-only pills, i.e. it suppresses ovulation, and reinforces the prolactin response to suckling ${ }^{9}$.

Diaz et al ${ }^{9}$ explored the mechanism of action of progesterone rings in lactating women by comparing ovarian function and prolactin levels between women who chose either a PVR or a Copper IUD at day 60 postpartum. Data were provided based on monthly follow up during one year of use. Frequency of breastfeeding and pregnancy rates in women who were relying only on lactational infertility were collected separately for comparative purposes ${ }^{9,12}$.

The women (defined as fully or exclusively breast-feeding) were instructed not to give their babies any liquid or solid food or water during the first 6 months postpartum and to use the breast as the only source of fluids and nutrients, with the exception of vitamin drops. Milk supplements were indicated only when inadequate infant growth was diagnosed. Non-dairy meals were introduced after the sixth postpartum month.

The endocrine profile during the first 8 months postpartum was assessed in a sub-group of breastfeeding women including 36 PVR-treated women and 28 IUDusers. Pre- and post-suckling prolactin (PRL) levels were measured at fortnightly intervals and E2 determinations and ovarian ultrasound were performed twice a week. Post-suckling PRL levels were significantly higher among PVR users $(n=20)$ compared with IUD users $(n=12)$; $p=0.009$. In PVR users, progesterone plasma levels ranged from 10 to $20 \mathrm{nmol} / \mathrm{L}$, at lower levels than in a normal luteal phase. Similarly, E2 levels were lower, and follicular growth was arrested at earlier stages in the PVR vs. the IUD groups (Figures $1 \& 2$ ). 
FIGURE 1 ESTRADIOL SERUM LEVELS BY

MONTH OF EXPOSURE

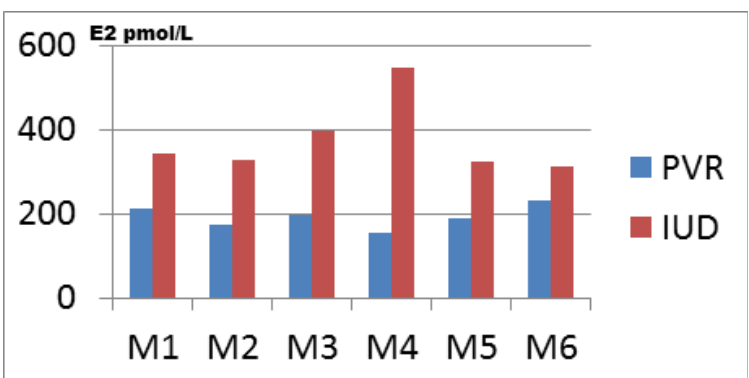

Mean of the Highest E2 Level in Lactating Women Treated with a Progesterone Vaginal Ring (PVR) or a Copper-T Device (IUD) $p<0.05$ except in month 6 (M6). (Adapted from Diaz et $\mathrm{al}^{9}$ )

FIGURE 2 FOLLICLE DIAMETER AMONG USERS OF PVR OR IUD (3-8 MOS. POSTPARTUM)

A significantly higher proportion of women (\%)

in the IUD (T-Cu) group

showed follicles $>15 \mathrm{~mm}$

than did those in the

PVR group $(p=0.0006$;

Fisher's exact test)

(Diaz et al. 1991) ${ }^{\circ}$

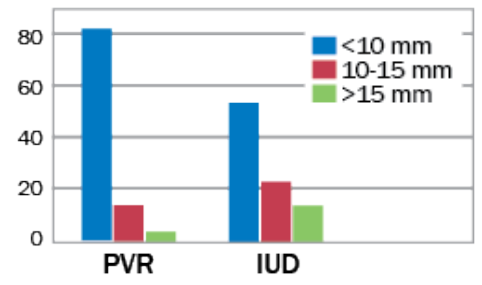

The authors concluded that progesterone increases the sensitivity of the breast-hypothalamic-pituitary system to suckling, as shown by the higher PRL levels in women using the PVR, and reinforces the mechanism of lactational infertility 9 . They also concluded that progesterone may affect the $\mathrm{GnRH}$-releasing process independently of suckling 9 . These results, therefore, support the efficacy of the PVR in suppressing ovulation for a longer duration as compared with "untreated" women who demonstrate resumption of follicle growth and possible ovulation even when fully breastfeeding.

\section{CONTRACEPTIVE EFFICACY OF THE PVR}

In the study by Diaz et al9, pregnancy rates at the end of the year were $0.6 \%$ in PVR users and $0.7 \%$ in IUD users. In another study that included the population of 236 breastfeeding only women, the pregnancy rates at one year were $39 \% 12$ (Table 1).

TABLE 1 CONTRACEPTIVE EFFICACY OF THE PVR IN NURSING WOMEN

\begin{tabular}{llll} 
& $\begin{array}{l}\text { PVR } \\
\text { Users }\end{array}$ & T-CU Users & $\begin{array}{l}\text { Untreated } \\
\text { Women }^{c}\end{array}$ \\
\hline Women & $246^{\mathrm{a}}$ & 442 & 226 \\
Pregnancies/WM & $1 / 2016$ & $2 / 3461$ & $50 / 1552$ \\
Pearl Index & 0.6 & 0.7 & 38.7
\end{tabular}

Adapted from Diaz et al 9 .

aPVR $5 \mathrm{mg}(n=76), 10 \mathrm{mg}(\mathrm{n}=109)$, or $15 \mathrm{mg}(\mathrm{n}=61)$. ' bWM= womanmonth; PVR and T-Cu were administered at day $60 \pm 5$ postpartum and the women were followed until month 14 postpartum. Untreated women were

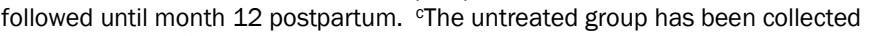

All women in the PVR and IUD groups were amenorrheic at admission. By the end of month 8 postpartum, $78 \%$ of PVR users and $29 \%$ of T-Cu users remained so. The PVR group experienced a significantly lower risk of bleeding $(p<0.0001)$ than did the IUD group.

Massai et al14 also studied the contraceptive efficacy and safety of the PVR compared to the Copper T 380A IUD (T-Cu) in breastfeeding women enrolled at three Chilean clinics. A total of 285 volunteers chose to use the PVR and 262 women used the T-Cu. Ring replacement was scheduled every 3 months. Volunteers continued in the study until weaning or completing the continuous use of four PVRs over one year. No pregnancies occurred in 2,320 and 2,183 woman-months of exposure with the PVR and the T-Cu, respectively.

The mean duration of lactational amenorrhea was 361 \pm 9 days in the PVR group and $198 \pm 8$ days in the T-Cu group $(p<0.0001)$. The proportion of amenorrheic women at the 6 th month postpartum was $87.4 \%$ among PVR users and $41.5 \%$ among T-Cu users $(p=0.0001)$.

These percentages were three- and six fold higher in the PVR than in the T-Cu groups at months 9 and 12, respectively ${ }^{14}$. The mean number of breastfeeding episodes was similar in both groups, decreasing from a mean of 10.1 episodes/day at month 3 to a mean of 5 episodes/day at month 14 postpartum. Infant weights were similar in both groups ${ }^{14}$.

In the Population Council's large comparative multicentric trial that compared 802 women using the PVR and 734 women who received a copper-T 380A IUD, the 1-year pregnancy rate with the ring was at 1.5 per 100 (431 women-years) and 0.5 per 100 in the copper-T 380A cohort (533 women-years). The percentage of women who were amenorrheic at 6 months postpartum was $67.4 \%$ in the PVR group and $43.7 \%$ among IUD users $(p=0.0001)$; and at month 12 , the rate of amenorrhea remained higher in the PVR group at $46.2 \%$ vs $16.1 \%$ in the IUD group ( $p=0.0001$ ). There was no difference between groups in the mean number of breastfeeding episodes per day (d) which was around 9 meals/day at initiation and 6 meals/d at 12 months ${ }^{15}$. In addition, the weight of the infants did not differ between PVR or IUD users except at 12 months and attributed to more supplements given in the IUD group ${ }^{15}$.

Preliminary results from a recent study of PVR vs. IUD use conducted in India (2012-2015) provides similar results with respect to rates of lactational amenorrhea and average daily breastfeeding episodes over time. Pregnancy rates were identical (1 pregnancy in each group) as were infant growth patterns (ICMR \& Population Council Internal Data Protocol 418). 


\section{SUMMARY}

Results of clinical trials completed to date support the following conclusions regarding the role of breast-feeding and use of the PVR to promote child spacing:

- Breastfeeding protects against pregnancy if a woman is fully breastfeeding and remains in amenorrhea; in this case her pregnancy risk will be about $0.9 \%$ at 6 months postpartum ${ }^{12}$.

- When a first bleeding occurs before the 6th month, the risk of pregnancy increases to $9 \%$ and higher ${ }^{5,12}$.

- The risk of experiencing the first bleeding is reduced while fully breastfeeding with a high number of nursing episodes per day and night, but nevertheless $25 \%$ and $50 \%$ of the women start to cycle by the end of the fifth and eight postpartum month, respectively ${ }^{3}$.

- Using a Progesterone Vaginal Ring (PVR) prolongs amenorrhea in a higher proportion of women compared to women who are breastfeeding only. At 6 months, $87.4 \%$ of PVR users are amenorrheic versus $41.5 \%$ in IUD users ${ }^{14}$.

- Users of a PVR show a higher suppression of ovarian follicles as compared with women using an IUD, with a majority of follicles at a diameter $<10 \mathrm{~mm}(82 \%)$, while IUD users show only $54 \%$ of follicles at $<10 \mathrm{~mm}$. Follicles of $>15 \mathrm{~mm}$ were seen in $4 \%$ of PVR users and $23 \%$ of IUD users ${ }^{9}$.

- In fully breastfeeding women, pregnancy rates at the end of one year are observed at $<1 \%$ in PVR users (treated) and at 39\% in breastfeeding women not using any other contraception ${ }^{9,12}$. This low failure rate of the PVR appears to have been replicated in a recent study in India.

Based on the review of the literature herein discussed, as well as preliminary findings from the recent study in India, it may be concluded that the PVR is effective in preventing an early return of follicle growth and ovulation, and preventing the return of cycling and fertility that may occur even in women who are fully breastfeeding9,12. A recent review of unmet need among postpartum women also suggests that in contexts where breastfeeding is common, counseling women about LAM and urging contraceptive adoption within six months of birth has programmatic rationale ${ }^{16}$.

These conclusions support the position of offering the PVR to women who plan to breastfeed in the context of postpartum contraceptive counseling. In this regard, WHO has issued the following recommendation for use of the PVR:

\section{"Women who breastfeed and are four or more weeks postpartum can use the PVR without restrictions (MEC category 1)".}

The Guideline Development Group advised that women who use the PVR must be actively breastfeeding (e.g. at least four breastfeeding episodes per day) to maintain the efficacy of the method $^{13}$.

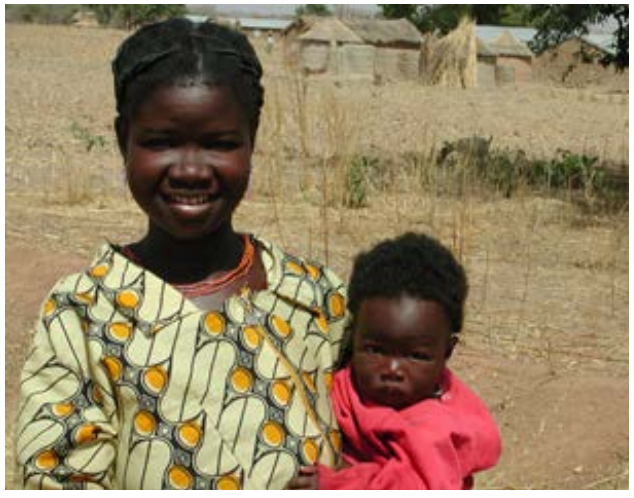

\section{REFERENCES}

1. World Health Organization (WHO), Programming Strategies for Postpartum Family Planning, Geneva: WHO, 2013.

2. Ross JA and Winfrey WL. Contraceptive use, intention to use and unmet need during the extended postpartum period. Int Fam Plan Perspect 2001;27:20-27.

3. Diaz S, Rodriguez G, Marshall G, del Pino G, Casado ME, Miranda P, et al. Breastfeeding pattern and the duration of lactational amenorrhea in urban Chilean women. Contraception 1988;38:37-51.

4. Diaz S, Rodriguez G, Peralta O, Miranda P, Casado ME, Salvatierra AM et al. Lactational amenorrhea and the recovery of ovulation and fertility in fully nursing Chilean women. Contraception 1988;38:53-67.

5. Kennedy KI, Rivera R, McNeilly AS. Consensus statement on the use of breastfeeding as a family planning method. Contraception 1989;39:477-96.

6. Kennedy KI, Visness CM. Contraceptive efficacy of lactational amenorrhoea. Lancet 1992;339:227-30.

7. Kennedy KI. Efficacy and effectiveness of LAM. Adv Exp Med Biol 2002;503:207-16.

8. Valdés V, Labbok MH, Pugin E, Perez A. The efficacy of the lactational amenorrhea method (LAM) among working women. Contraception 2000;62:217-19.

9. Diaz S, Miranda P, Brandeis A, Cardenas H, Croxatto HB. Mechanism of action of progesterone as contraceptive for lactating women. Ann N Y Acad Sci 1991;626:11-21.

10. Fabic MS and Choi Y. Assessing the quality of data regarding use of the lactational amenorrhea method. Stud Fam Plann 2013;44:205221.

11. Labbok MH, High-Laukaran V, Peterson AE, Fletcher V, von Hertzen $H$, Van Look PF. Multicenter study of the lactational amenorrhea method (LAM): I (Efficacy, duration and implications for clinical application). Contraception 1997;55:327-336.

12. Diaz S, Aravena R, Cardenas $\mathrm{H}$, et al. Contraceptive efficacy of lactational amenorrhea in urban Chilean women. Contraception 1991;43:335-352.

13. WHO Medical Eligibility Criteria for Contraceptive Use. Fifth edition, 2015. http://apps.who.int/iris/bitstream/10665/172915/1/ WHO RHR 15.07 eng.pdf

14. Massai R, Miranda $P$, Valdés $P$, Lavin $P$, Zepeda A, Casado ME et al. Preregistration study on the safety and contraceptive efficacy of a progesterone-releasing vaginal ring in Chilean nursing women. Contraception 1999;60:9-14

15. Sivin I, Diaz S, Croxatto HB Miranda P, Shaaban M, Sayed EH, et al. Contraceptives for lactating women: a comparative trial of a progesterone-releasing vaginal ring and the copper T 380A IUD. Contraception 1997;55:225-32.

16. Cleland J, Shah IH, Benova L. A fresh look at the level of unmet need for family planning in the postpartum period, its causes and program implications. International Perspectives on Sexual and Reproductive Health 2015; 41:155-162.

\section{CONTACT INFORMATION}

For more information about the Council, please refer to our website at www.popcouncil.org 